\title{
Evaluation of Antimicrobial Activity of Two Endodontic Sealers: Zinc Oxide with Thyme Oil and Zinc Oxide Eugenol against Root Canal Microorganisms- An in vitro Study
}

\author{
${ }^{1}$ Nilima R Thosar, ${ }^{2}$ Manoj Chandak, ${ }^{3}$ Manohar Bhat, ${ }^{4}$ Silpi Basak
}

\begin{abstract}
Aim: The present study was aimed to find out and compare the antimicrobial effect of the paste containing zinc oxide cement mixed with thyme oil $(\mathrm{ZO}+\mathrm{Th}$ oil) with that of the paste containing zinc oxide and eugenol $(\mathrm{ZO}+\mathrm{E})$ against Staphylococcus aureus, Escherichia coli, Enterococcus faecalis, and Pseudomonas aeruginosa, common root canal pathogens of deciduous teeth.
\end{abstract}

Materials and methods: An in vitro antimicrobial effect was carried out by the agar diffusion method. The ZO + Th oil paste was filled in the punched holes of Mueller Hinton agar at two equidistant points. The same was followed for $\mathrm{ZO}+\mathrm{E}$ paste. For 24 hours, all the plates were incubated at a temperature of $37^{\circ} \mathrm{C}$. The inhibition zones in millimeters around the wells were calculated. There were 6 times repetitions of the test for each microorganism. Data were tabulated and analyzed statistically using one-way analysis of variance (ANOVA) and Tukey's post hoc comparison test. Level of significance for the tests was $5 \%$.

Results: Zones of bacterial inhibition were highest for ZO + Th oil paste against the pathogenic microorganisms $S$. aureus, followed by $E$. coli, E. faecalis, P. aeruginosa while for $Z O+E$ paste, the decreasing order against pathogenic microorganisms was E. coli, S. aureus, E. faecalis, and $P$. aeruginosa. Statistically significant difference was found in both the pastes, ZO + Th oil paste and ZO + E paste.

Conclusion: ZO + Th oil paste showed higher levels of antimicrobial effect against the root canal pathogens.

\footnotetext{
${ }^{1,4}$ Professor, ${ }^{2,3}$ Professor and Head

${ }^{1}$ Department of Pedodontics and Preventive Dentistry, Sharad Pawar Dental College \& Hospital, Datta Meghe Institute of Medical Sciences, Wardha, Maharashtra, India

${ }^{2}$ Department of Conservative Dentistry and Endodontics, Sharad Pawar Dental College \& Hospital, Datta Meghe Institute of Medical Sciences, Wardha, Maharashtra, India

${ }^{3}$ Department of Pedodontics and Preventive Dentistry, Jaipur Dental College, Jaipur, Rajasthan, India

${ }^{4}$ Department of Microbiology, Jawaharlal Nehru Medical College Datta Meghe Institute of Medical Sciences, Wardha, Maharashtra India

Corresponding Author: Nilima R Thosar, Professor, Department of Pedodontics and Preventive Dentistry, Sharad Pawar Dental College \& Hospital, Datta Meghe Institute of Medical Sciences Wardha, Maharashtra, India, Phone: +917152287701, e-mail: drnthosar@rediffmail.com
}

Keywords: Antimicrobial efficacy, Zinc oxide eugenol paste, Zinc oxide mixed with thyme oil paste.

How to cite this article: Thosar NR, Chandak M, Bhat M, Basak S. Evaluation of Antimicrobial Activity of Two Endodontic Sealers: Zinc Oxide with Thyme Oil and Zinc Oxide Eugenol against Root Canal Microorganisms-An in vitro Study. Int J Clin Pediatr Dent 2018;11(2):79-82.

Source of support: Nil

Conflict of interest: None

\section{INTRODUCTION}

Microbial infections in root canals of primary teeth are polymicrobial in nature. ${ }^{1}$ Pulpectomy of primary teeth includes biomechanical preparation and use of intracanal dressing with antibacterial properties. The success of endodontic treatment depends on the removal of infected bacteria. ${ }^{2}$ There are various methods: proper debridement with instrumentation, antibacterial irrigations, and antibacterial filling materials. ${ }^{3}$

Due to the presence of numerous accessory canals in primary teeth, intracanal dressings may fail to remove these microorganisms from inaccessible areas. So, it is important to use an obturating material which has antibacterial properties to act on such microorganisms of inaccessible areas of root canals of primary teeth. Due to antibacterial efficacy, thyme oil shows its potential to be used in dentistry. ${ }^{4}$

Thymol inhibits the bacterial growth in oral cavity. It shows potential to inhibit the dental infection also. 5,6 Thymol and carvacrol are its important constituents in 20 to $40 \%$. Others include B-cymene, pinene and triterpenic acid, menthone, borneol, linalool, and cineole. ${ }^{7}$ As there are no studies available in the literature about the use of thyme oil as obturating material in deciduous teeth, the present study was carried out by using $\mathrm{ZO}+$ Th oil paste and compared with $\mathrm{ZO}+\mathrm{E}$ paste.

Therefore, the present study was aimed to find out the antimicrobial activity of $\mathrm{ZO}+$ Th oil paste with that of $\mathrm{ZO}+\mathrm{E}$ paste.

\section{MATERIALS AND METHODS}

The present study was an in vitro study. It was approved by the institutional ethical committee of Datta Meghe 
Table 1: Zones of bacterial growth inhibition in $\mathrm{mm}$ of $Z O+$ Th oil against four bacterial strains

\begin{tabular}{|c|c|c|c|c|c|c|c|c|}
\hline \multirow[b]{2}{*}{ Material } & \multirow[b]{2}{*}{$n$} & \multirow[b]{2}{*}{ Mean } & \multirow[b]{2}{*}{ Std. deviation } & \multirow[b]{2}{*}{ Std. error } & \multicolumn{2}{|c|}{$95 \%$ confidence interval for mean } & \multirow[b]{2}{*}{ Minimum } & \multirow[b]{2}{*}{ Maximum } \\
\hline & & & & & Lower bound & Upper bound & & \\
\hline S. aureus & 6 & 36.33 & 1.36 & 0.55 & 34.89 & 37.76 & 35.00 & 38.00 \\
\hline E. coli & 6 & 35.33 & 2.73 & 1.11 & 32.46 & 38.20 & 32.00 & 38.00 \\
\hline E. faecalis & 6 & 28.00 & 1.78 & 0.73 & 26.12 & 29.87 & 26.00 & 30.00 \\
\hline$P$. aeruginosa & 6 & 21.33 & 7.22 & 2.95 & 13.74 & 28.92 & 14.00 & 30.00 \\
\hline
\end{tabular}

Institute of Medical Sciences. In this study, zinc oxide was combined with thyme oil. It was compared with zinc oxide and eugenol combination paste. Thyme oil was procured from Aromatantra, Mumbai.

The powder-liquid ratio of pastes was as per specifications of Tchaou et al. ${ }^{3}$ A quantity of powder $0.2 \mathrm{gm}$ was mixed with $0.07 \mathrm{cc}$ oil. Mixing of powder with liquid was carried out with the help of spatula on a dry glass slab. ${ }^{8}$ Microorganisms from the microbiology department of Jawaharlal Nehru Medical College, Wardha, were used for the study.

Microbial strains studied were: S. aureus [American Type Culture Collection (ATCC) 25923], E. faecalis (ATCC 29212), E. coli (ATCC 25922), P. aeruginosa (ATCC 27853). Mueller Hinton agar was used as the growth medium for testing the susceptibility of S. aureus, E. coli, E faecalis, and $P$ aeruginosa. ${ }^{9}$

Stock culture of test microorganism was poured in brain heart infusion broth $(5 \mathrm{~mL})$. Incubation was done at $37^{\circ} \mathrm{C}$ for 24 hours. Microorganisms were then subcultured on blood agar; again incubated for the same time and same temperature. Colonies of microorganisms were inoculated in the medium of nutrient broth for the time of 6 hours. Its density was adjusted to 0.5 as per McFarland scale. ${ }^{10}$ Petri dishes $(90 \mathrm{~mm})$ with $4 \mathrm{~mm}$ thick Mueller Hinton agar was used. All the work was done under laminar air flow chamber.

The lawn technique was used for uniform distribution of bacterial dilutions. Care was taken while punching the holes in agar; the mean diameter of holes was $6 \mathrm{~mm}$ at the level of equal distance from each other. Holes were punched with open end of micropipette. Freshly prepared root canal filling paste was then placed in the hole. It was kept at room temperature for 2 hours.
The procedure was repeated for 6 times for every microorganism. The plates were incubated for 24 hours. Next day, the diameter of growth inhibitory zones was calculated by using the antibiotic zone scale of HiMedia. ${ }^{8}$ Wider zones were read as having a higher antibacterial effect against the specific microorganism. ${ }^{9}$

Data were analyzed statistically using ANOVA and Tukey's post hoc test at a significance level of 5\% using the GraphPad Prism 4 software.

\section{RESULTS}

For $\mathrm{ZO}+$ Th oil paste, the diameter in mm of the inhibition zones for S. aureus was $36.33 \pm 1.36$, for E. coli, it was 35.33 \pm 2.73 , for E. faecalis, it was $28 \pm 1.78$, and for P. aeruginosa, it was $21.33 \pm 7.22$ (Table 1 ).

Table 2 is suggestive of the one-way ANOVA of bacterial inhibition zones for the $\mathrm{ZO}+\mathrm{Th}$ oil paste group in which the difference between and within groups was statistically significant (p-value: 0.0001, $\mathrm{p}<0.05$ ).

Table 3 shows multiple comparisons: Tukey test was done for the $\mathrm{ZO}+$ Th oil paste group to evaluate the inhibitory zones of bacteria. It showed that the difference was statistically significant for $S$. aureus and E. faecalis with a p-value 0.004 , which is less than 0.05 ; however, significant differences were also found for other bacteria also, i.e.,

Table 2: One-way ANOVA of zones of bacterial growth inhibition of $\mathrm{ZO}+$ Th oil against four bacterial strains

\begin{tabular}{llllll}
\hline $\begin{array}{l}\text { Source of } \\
\text { variation }\end{array}$ & $\begin{array}{l}\text { Sum of } \\
\text { squares }\end{array}$ & Df & $\begin{array}{l}\text { Mean } \\
\text { square }\end{array}$ & $f$-value & $p$-value \\
\hline Between groups & 2756.80 & 4 & 689.20 & 53.17 & $0.0001 \mathrm{~S}$, \\
Within groups & 324.00 & 25 & 12.96 & & $\mathrm{p}<0.05$ \\
\hline Total & 3080.80 & 29 & & & \\
\hline
\end{tabular}

S: Significant

Table 3: Multiple comparison: Tukey test of zones of bacterial growth inhibition of ZO + Th oil against four bacterial strains

\begin{tabular}{lllllll}
\hline & & & & \multicolumn{2}{c}{$95 \%$ confidence interval } \\
\cline { 5 - 7 } Microorganisms & & Mean difference & Std. error & p-value & Lower bound & Upper bound \\
\hline S. aureus & E. coli & 1.00 & 2.07 & 0.988, NS & -5.10 & 7.10 \\
& E. faecalis & 8.33 & 2.07 & 0.004, S & 2.22 & 14.43 \\
& P. aeruginosa & 15.00 & 2.07 & 0.0001, S & 8.89 & 21.10 \\
E. coli & E. faecalis & 7.33 & 2.07 & 0.013, S & 1.22 & 13.43 \\
& P. aeruginosa & 14.00 & 2.07 & 0.0001, S & 7.89 & 20.10 \\
E. faecalis & P. aeruginosa & 6.66 & 2.07 & 0.027, S & 0.56 & 12.77 \\
\hline
\end{tabular}

NS: Not significant; S: Significant 
Table 4: Zones of bacterial growth inhibition in $\mathrm{mm}$ of ZOE against four bacterial strains

\begin{tabular}{lllllllll}
\hline & & & & & \multicolumn{2}{l}{ 95\% confidence interval for mean } & \\
Microorganisms & $n$ & Mean & Std. deviation & Std. error & Lower bound & Upper bound & Minimum & Maximum \\
\hline S. aureus & 6 & 16.00 & 0.00 & 0.00 & 16.00 & 16.00 & 16.00 & 16.00 \\
E. coli & 6 & 19.00 & 1.09 & 0.44 & 17.85 & 20.14 & 18.00 & 20.00 \\
E. faecalis & 6 & 10.83 & 1.47 & 0.60 & 9.28 & 12.37 & 9.00 & 12.00 \\
P. aeruginosa & 6 & 10.33 & 0.51 & 0.21 & 9.79 & 10.87 & 10.00 & 11.00 \\
\hline
\end{tabular}

Table 5: One-way ANOVA of zones of bacterial growth inhibition of ZOE against four bacterial strains

\begin{tabular}{llllll}
\hline & Sum of & & Mean & & \\
Source of variation & squares & Df & square & f-value & $p$-value \\
\hline Between groups & 352.20 & 4 & 88.05 & 95.70 & $0.0001 \mathrm{~S}$ \\
Within groups & 23.00 & 25 & 0.92 & & $p<0.05$ \\
\hline Total & 375.20 & 29 & & & \\
\hline S: Significant & & & &
\end{tabular}

S: Significant

between $S$. aureus and P. aeruginosa with p-value 0.0001; between E. coli and E. faecalis $(0.013, \mathrm{p}<0.05)$; between E. coli and P. aeruginosa, 0.0001; and between E. faecalis and $P$. aeruginosa (p-value: 0.027, p <0.05).

The difference for the inhibitory zones between $S$. aureus and E. coli $(0.988, \mathrm{p}<0.05)$ was not significant statistically. Diameters in $\mathrm{mm}$ of the inhibitory zones for other microorganisms in the $\mathrm{ZO}+\mathrm{E}$ paste group in descending order were: E. coli $(19 \pm 1.09)$, S. aureus $(16 \pm$ $0.00)$, E. faecalis $(10.83 \pm 1.47)$, and P. aeruginosa $(10.33 \pm$ 0.51 ) (Table 4) respectively.

In Table 5, one-way ANOVA for the $\mathrm{ZO}+\mathrm{E}$ paste group, differences for inhibitory zones of bacteria are found to be statistically significant (p-value: 0.0001, $\mathrm{p}<0.05$ ) between and within groups. Table 6 shows multiple comparisons: Tukey test for inhibitory zones of bacteria and it was observed that the difference between $S$. aureus and E. coli was found to be statistically significant (0.0001, $\mathrm{p}<0.05)$. For other microorganism, the difference was found to be statistically significant like $S$. aureus vs $E$. faecalis (0.0001, $\mathrm{p}<0.05)$; S. aureus vs P. aeruginosa (0.0001, $\mathrm{p}<0.05)$; E. coli vs E. faecalis $(0.0001, \mathrm{p}<0.05)$; and E. coli vs E. faecalis $(0.002, \mathrm{p}<0.05)$.

The difference for E. faecalis vs P. aeruginosa (0.893, $\mathrm{p}<0.05)$ was not statistically significant.

\section{DISCUSSION}

Infections of root canals in primary teeth are polymicrobial in nature. Numerous materials have been tried in dentistry for obturation of deciduous teeth. Zinc oxide is widely used in dentistry.

There are disadvantages associated with this material like slow resorption of ZOE as compared with physiologic resorption of deciduous tooth, deflection of succedaneous tooth, irritation to tissue at periapical area of tooth, bone and cementum necrosis and tooth discoloration. ${ }^{11}$ Thyme oil is found in European countries around Mediterranean and said to belong to around 300 species of shrubs and plants.

Essential oil from thyme plant is prepared from its leaves and flowers by the method of steam distillation. Thyme oil is useful in certain conditions like relief from gastritis and enterocolitis. It is also found to be useful in oral thrush. It can be used for patients suffering from asthma and respiratory infections. Other uses of it are treatment of swelling caused by gout or rheumatic problems, for backache, joint pains, and sciatica.

Thyme oil is also used for other conditions like vaginitis, urinary infections, etc. ${ }^{7}$ Very few review articles are available in the literature mentioning the use of thyme oil in dentistry. Antibacterial effects of thymol have been found in Listerine. ${ }^{12}$ The study of Sköld-Larsson et $\mathrm{al}^{13}$ had shown the use of thymol in the form of dental varnish to reduce the Streptococcus mutans levels in supragingival plaque near the bracket in patients with orthodontic brackets. Thyme oil and clove oil together had shown the antimicrobial effect against E. coli, S. aureus, and C. albicans at various concentrations of the extracts. ${ }^{14-16}$ Thosar et al $^{17}$ in their study carried out in 2013 had shown the antimicrobial susceptibility for

Table 6: Multiple comparison: Tukey test of zones of bacterial growth inhibition of ZOE against four bacterial strains

\begin{tabular}{lllllrr}
\hline & & & & & \multicolumn{2}{c}{ 95\% confidence interval } \\
\cline { 5 - 7 } Microorganisms & & Mean difference & Std. error & p-value & Lower bound & Upper bound \\
\hline S. aureus & E. coli & -3.00000 & 0.55377 & $0.0001, \mathrm{~S}$ & -4.62 & -1.37 \\
& E. faecalis & 5.16667 & 0.55377 & $0.0001, \mathrm{~S}$ & 3.54 & 6.79 \\
E. coli & P. aeruginosa & 5.66667 & 0.55377 & $0.0001, \mathrm{~S}$ & 4.04 & 7.29 \\
& E. faecalis & 8.16667 & 0.55377 & $0.0001, \mathrm{~S}$ & 6.54 & 9.79 \\
E. faecalis & P. aeruginosa & 8.66667 & 0.55377 & $0.0001, \mathrm{~S}$ & 7.04 & 10.29 \\
\hline
\end{tabular}

NS: Not significant; S: Significant 
thyme oil for $E$. coli which was with minimum inhibitory concentration (MIC): $2 \mu \mathrm{L} / \mathrm{mL}$, minimum bactericidal concentration (MBC): $8 \mu \mathrm{L} / \mathrm{mL}$; for C. albicans, MIC, MBC: $16 \mu \mathrm{L} / \mathrm{mL}$; for E. faecalis MIC, MBC: $32 \mu \mathrm{L} / \mathrm{mL}$ and for $S$. aureus MIC, MBC: $32 \mu \mathrm{L} / \mathrm{mL}$ respectively. The present study suggests that use of thyme oil when mixed with zinc oxide powder in the form of paste showed wider zones of inhibition for S. aureus, E. faecalis, E. coli, and P. aeruginosa in comparison with zinc oxide powder which was mixed with eugenol oil.

As the $\mathrm{ZO}+\mathrm{Th}$ oil paste showed more antibacterial activity in comparison with ZOE paste, it can be successfully used in pediatric dentistry as an obturating material in primary teeth. But further elaborative animal experimental studies can prove its tissue biocompatibility and toxicity properties.

\section{CONCLUSION}

A new material, i.e., $\mathrm{ZO}+$ Th oil paste, used in this study had shown strong antibacterial activity against all the root canal microorganisms which were studied and showed its superiority over the zinc oxide + eugenol paste group.

This material will definitely prove its success in pediatric dentistry as an obturating material for primary teeth.

\section{REFERENCES}

1. Ruviére DB, Leonardo MR, da Silva LA, Ito IY, Nelson-Filho P. Assessment of the microbiota in root canals of human primary teeth by checkerboard DNA-DNA hybridization. J Dent Child 2007 May-Aug;74(2):118-123.

2. Tronstad L. Recent development in endodontic research. Scand J Dent Res 1992 Feb;100(1):52-59.

3. Tchaou WS, Turng BF, Minah GF, Coil JA. In vitro inhibition of bacteria from root canals of primary teeth by various dental materials. Pediatr Dent 1995 Sep-Oct;17(5):351-355.

4. Meeker HG, Linke HA. The antibacterial action of eugenol, thyme oil, and related essential oils used in dentistry. Compendium 1988 Jan;9(1):32, 34-35, 38.
5. Shapiro S, Guggenheim B. The action of thymol on oral bacteria. Oral Microbiol Immunol 1995 Aug;10(4):241-246.

6. Yu D, Pearson SK, Bowen WH, Luo D, Kohut BE, Harper DS. Caries inhibition efficacy of an antiplaque/antigingivitis dentifrice. Am J Dent 2000 Sep;13(Spec No):14C-17C.

7. Ratan, R. Handbook of aromatherapy. A complete guide to essential and carrier oils, their application and therapeutic use for holistic health and wellbeing. 2nd ed. Mumbai: Institute of Holistic Health Sciences; 2006. p. 37, 43, 48.

8. Baldota N, Bendgude V. Comparative evaluation of antimicrobial efficacy of three calcium hydroxide pastes with zinc oxide eugenol used as root canal filling materials in primary teeth: an in vitro study. Int J Dent Health Sci 2014;1(3): 311-321.

9. Aravind, Gopikrishna V, Kandaswamy D, Jeyavel RK. Comparative evaluation of the antimicrobial efficacy of five endodontic root canal sealers against Enterococcus faecalis and Candida albicans. J Conserv Dent 2006;9(1):2-12.

10. Shah A, Jani M, Shah H, Chaudhary N, Shah A. Antimicrobial effect of clove oil (laung) extract on Enterococcus faecalis. J Adv Oral Res 2014 Dec;5(3):36-38.

11. Praveen P, Anantharaj A, Venkataraghavan K, Rani R, Sudhir R, Jaya AR. A review of obturating materials for primary teeth. SRM Univ J Dent Sci 2011 Jan-Mar;2(1):42-44.

12. Kato T, Iijima $H$, Ishihara $K$, Kaneko T, Hirai K, Naito Y, Okuda K. Antibacterial effects of Listerine on oral bacteria. Bull Tokyo Dent Coll 1990 Nov;31(4):301-307.

13. Sköld-Larsson K, Borgström MK, Twetman S. Effect of an antibacterial varnish on lactic acid production in plaque adjacent to fixed orthodontic appliances. Clin Oral Investig 2001 Jun;5(2):118-121.

14. Nascimento GG, Locatelli J, Freitas PC, Silva GL. Antibacterial activity of plant extracts and phytochemicals on antibioticresistant bacteria. Braz J Microbiol 2000 Oct-Dec;31(4): 314-325.

15. Hili P, Evans CS, Veness RG. Antimicrobial action of essential oils: the effect of dimethylsulphoxide on the activity of cinnamon oil. Lett Appl Microbiol 1997 Apr;24(4):269-275.

16. Nzeako BC, Al-Kharousi ZS, Al-Mahrooqui Z. Antimicrobial activities of clove and thyme extracts. Sultan Qaboos Univ Med J 2006 Jun;6(1):33-39.

17. Thosar N, Basak S, Bahadure RN, Rajurkar M. Antimicrobial efficacy of five essential oils against oral pathogens: an in vitro study. Eur J Dent 2013 Sep;7(Suppl 1):S71-S77. 